\title{
Glucocorticoid receptor haplotype and metabolic syndrome: the Lifelines cohort study
}

\author{
Vincent L Wester ${ }^{1,3}$, Jan W Koper, ${ }^{1,3}$, Erica L T van den Akker ${ }^{2,3}$, Oscar H Franco ${ }^{4}$, \\ Ronald P Stolk ${ }^{5}$ and Elisabeth F C van Rossum ${ }^{1,3,6}$ \\ ${ }^{1}$ Department of Internal Medicine, ${ }^{2}$ Department of Pediatrics, ${ }^{3}$ Obesity Center CGG, ${ }^{4}$ Department of Epidemiology, \\ Eramus MC, University Medical Center Rotterdam, Rotterdam, The Netherlands, ${ }^{5}$ Department of Epidemiology, \\ University Medical Center Groningen, Groningen, The Netherlands, and 6 Lifelines Cohort Study, Groningen, \\ The Netherlands
}

Correspondence should be addressed to E F C van Rossum Email

e.vanrossum@erasmusmc.nl

\begin{abstract}
Objective: An excess of glucocorticoids (Cushing's syndrome) is associated with metabolic syndrome (MetS) features. Several single-nucleotide polymorphisms (SNPs) in the glucocorticoid receptor (GR) gene influence sensitivity to glucocorticoids and have been associated with aspects of MetS. However, results are inconsistent, perhaps due to the heterogeneity of the studied populations and limited samples. Furthermore, the possible association between functional GR SNPs and prevalence of MetS remains unexplored.

Design: Cross-sectional population-based cohort study.

Methods: MetS presence and carriage of functional GR SNPs (Bc/l, N363S, ER22/23EK, GR-9beta) were determined in 12552 adult participants from Lifelines, a population-based cohort study in the Netherlands. GR SNPs were used to construct GR haplotypes.

Results: Five haplotypes accounted for $99.9 \%$ of all GR haplotypes found. No main effects of functional GR haplotypes on MetS were found, but the association of GR haplotype 4 (containing N363S) with MetS was influenced by interaction with age, sex and education status $(P<0.05)$. Stratified analysis revealed that haplotype 4 increased MetS presence in younger men (at or below the median age of 47 ; odds ratio $1.77, P=0.005$ ) and in people of low education status (odds ratio $1.48, P=0.039$ ).

Conclusions: A glucocorticoid receptor haplotype that confers increased sensitivity to glucocorticoids appears to increase the risk of metabolic syndrome, but only among younger men and less educated individuals, suggesting gene-environment interactions.
\end{abstract}

\section{Introduction}

The metabolic syndrome (MetS) is a cluster of cardiometabolic risk factors associated with cardiovascular disease, diabetes and increased mortality $(1,2)$. An individual is considered to have MetS if three out of the following five risk factors are present: abdominal obesity, hypertension, high triglycerides, low HDL cholesterol and insulin resistance (1).
Approximately one-fourth of adults in Europe are reported to fulfill the criteria for MetS (3), and MetS is known to double the risk of incident cardiovascular disease (2).

Glucocorticoid hormones, of which cortisol is the most important in humans, affect metabolism, behavior and circulation (4). An excess of glucocorticoids, which
() 2016 European Society of Endocrinology Printed in Great Britain
Published by Bioscientifica Ltd. 
occurs in endogenous hypercortisolism as well as due to glucocorticoid administration, results in Cushing's syndrome (CS) (5). CS commonly leads to central obesity and MetS features (5). Furthermore, slight increases in long-term cortisol exposure have been linked to increases in MetS presence, cardiovascular disease and obesity $(6,7)$.

The tissue effects of glucocorticoids are influenced by glucocorticoid sensitivity, which is partly determined by functional single-nucleotide polymorphisms (SNPs) in the glucocorticoid receptor (GR) gene. These polymorphisms are associated with cardiometabolic risk factors in an age-dependent manner $(4,8)$. The $B c l$ I polymorphism increases glucocorticoid sensitivity in vivo as assessed using dexamethasone suppression testing (9) and has been associated with increased BMI, central adiposity and insulin resistance $(10,11)$. The N363S polymorphism increases the in vivo sensitivity to glucocorticoids, as well as the transactivational capacity of the GR $(12,13,14)$, which is presumed to be responsible for most of the metabolic effects of glucocorticoids (15). In line with this, N36S carriage has been associated with increased BMI and higher LDL cholesterol in the elderly $(16,17)$. In contrast, the ER22/23EK polymorphism has been shown to decrease GR transactivation (13). ER22/23EK has been associated with a beneficial metabolic profile with subtle increases in lean mass in younger individuals, and increased insulin sensitivity, lower LDL cholesterol and decreased cerebrovascular pathology in the elderly $(18,19,20)$. We also showed previously that the GR-9beta polymorphism does not affect GR transactivation, but reduces the transrepression activity of the GR, and thereby the immunosuppressive actions of glucocorticoids $(15,21)$. Carriage of GR-9beta has been associated with an increased incidence of coronary heart disease (22). These functional GR polymorphisms show a high level of linkage disequilibrium and can be integrated to distinguish five different haplotypes of the GR gene (23).

To the best of our knowledge, no study has investigated the associations between GR haplotypes and the presence of MetS. Previous studies indicate that variations in the GR may affect the cardiometabolic profile in an age-dependent manner. Therefore, we aimed to study the associations between GR haplotypes and MetS in a large population-based cohort, providing an opportunity to investigate how this association may vary in subgroups with respect to age, sex and socioeconomic status.

\section{Subjects and methods}

\section{Participants and procedures}

Lifelines is a multi-disciplinary prospective populationbased cohort study examining in a unique three-generation design, the health and health-related behaviors of 167729 persons living in the north of the Netherlands. It uses a broad range of investigative procedures in assessing the biomedical, sociodemographic, behavioral, physical and psychological factors, which contribute to the health and disease of the general population, with a special focus on multi-morbidity and complex genetics (24). Lifelines is a facility that is open for all researchers. Information on the application and data access procedure is summarized on www.lifelines.net. Detailed information on all collected variables can be found in the online Lifelines Data Catalogue (https://catalogue.lifelines.nl/).

Each participant was invited for a site visit that included a fasting venipuncture and a physical examination including measurement of blood pressure, weight, height and waist circumference. In addition, all participants were asked to fill out a set of questionnaires, including an extensive medical history. We included all adult participants in whom genome-wide association study (GWAS) and cardiometabolic data were available $(n=12$ 552). This study was approved by the Medical Ethics Review Committee of the University Medical Center Groningen. All study procedures were carried out in accordance with the Declaration of Helsinki, and all participants provided written informed consent.

\section{Laboratory measurements and MetS diagnosis}

In each participant, blood was drawn after an overnight fast. Glucose, triglycerides and HDL cholesterol were determined using routine laboratory procedures. MetS presence was defined according to the commonly used NCEP ATPIII criteria (25), when participants fulfilled at least three of the following five criteria: abdominal obesity (waist circumference $>102 \mathrm{~cm}$ in men, $>88 \mathrm{~cm}$ in women), elevated triglycerides (serum triglycerides $>1.7 \mathrm{mmol} / \mathrm{L}$ and/or use of lipid-lowering medication), reduced HDL cholesterol (serum $\mathrm{HDL}<1.0 \mathrm{mmol} / \mathrm{L}$ in men and $<1.3 \mathrm{nmol} / \mathrm{L}$ in women, and/or use of lipid-lowering medication), elevated blood pressure (systolic $>130$ and/ or diastolic $>85 \mathrm{mmHg}$ and/or use of antihypertensives) and elevated fasting glucose (fasting plasma glucose $>5.6 \mathrm{mmol} / \mathrm{L}$, and/or use of blood glucose-lowering medication and/or diagnosis of type 2 diabetes mellitus). 
Table 1 Baseline characteristics. Differences between females and males were tested using Mann-Whitney $U$ tests (continuous variables) or $\chi^{2}$ tests (categorical variables).

Age (years), median (IQR)
Smoking status (\%)
Current
Past
Education level (\%)
Lower
Middle
Higher
Cardiometabolic parameters, median (IQR)
Body mass index $\left(\mathrm{kg} / \mathrm{m}^{2}\right)$
Waist circumference $(\mathrm{cm})$
Triglycerides (mmol/L)
HDL cholesterol (mmol/L)
Glucose (mmol/L)
Systolic blood pressure $(\mathrm{mmHg})$
Metabolic syndrome $(\%)$

\begin{tabular}{c}
\hline Females $(n=7327)$ \\
\hline $47(41-55)$ \\
23.8 \\
35.2 \\
19.6 \\
55.2 \\
22.8 \\
$25.4(22.9-28.5)$ \\
$88(80-96)$ \\
$0.93(0.70-1.31)$ \\
$1.5(1.3-1.8)$ \\
$4.9(4.6-5.2)$ \\
$123(114-134)$ \\
19.6 \\
\hline
\end{tabular}

\begin{tabular}{c}
\hline Males $(n=5225)$ \\
\hline $48(41-57)$ \\
27.8 \\
38.7 \\
22.9 \\
46.5 \\
29.1 \\
$26.3(24.3-28.6)$ \\
$96(90-103)$ \\
$1.21(0.88-1.75)$ \\
$1.2(1.0-1.4)$ \\
$5.1(4.8-5.5)$ \\
$132(123-142)$ \\
25.1
\end{tabular}

\begin{tabular}{r}
\hline P value \\
\hline 0.025 \\
$<0.001$
\end{tabular}

$<0.001$

HDL, high-density lipoprotein; IQR, interquartile range.

In addition to the ATPIII criteria, we used MetS criteria of the International Diabetes Federation (IDF) in sensitivity analyses, to examine the robustness of our findings (26).

\section{Genomic analysis}

Genotyping was performed using the Illumina HumanCytoSNP GWAS platform. The GWAS set was enriched using imputation with 1000 genomes as a reference set. From this enriched GWAS dataset, genotypes of functional GR SNPs (ER22/23EK, rs6189 and rs6190; N363S rs56149945; BclI, rs41423247; GR-9ק, rs6198) were extracted using PLINK version 1.08p (Shaun Purcell, Harvard University) (27). PHASE version 2.1 (Matthew Stephens Lab, University of Chicago) was used to construct GR haplotypes based on these SNPs $(28,29)$.

\section{Statistical analysis}

SPSS version 21 was used for descriptive statistics, and $\mathrm{R}$ statistics (version 3.2.1) was used for regression analysis. The association between GR haplotype status (carriers vs non-carriers) and MetS was studied using logistic regression. Analyses were adjusted for covariates with a significant influence on MetS presence $(P<0.05)$, which included smoking status, education level, age and sex. Smoking status was defined as no smoking, past smoking for at least one year and current smoking. Education level was stratified in three categories of attained education levels: low, middle or high. To adjust the models for smoking and education status, dummy variables were created for low education status, high education status, past smoking and current smoking. To study interaction effects between covariates and GR haplotypes, we studied whether addition of an interaction term (haplotypexcovariate) significantly changed the model, using the likelihood ratio test. Significant interactions were explored using stratified analysis with Bonferroni adjustment for multiple testing. $P$ values of $<0.05$ were considered to indicate statistical significance.

\section{Results}

Baseline characteristics are described in Table 1. In the total study population, MetS prevalence was $21.9 \%$ and was higher in men than in women (25.1 vs $19.6 \%$, $P<0.001$ ). Five haplotypes accounted for over $99.9 \%$ of all GR haplotypes, the frequencies of which are depicted in Fig. 1. Haplotype frequencies were similar to the

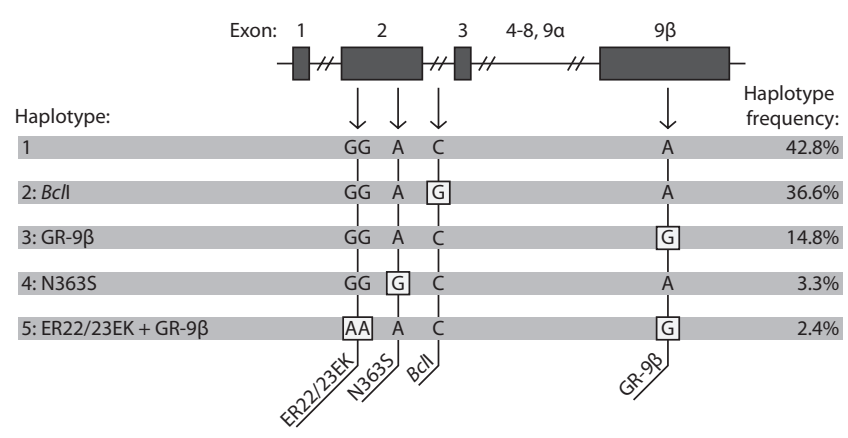

\section{Figure 1}

Glucocorticoid receptor haplotype frequencies. 
Table 2 Association between functional glucocorticoid receptor haplotype carrier status ( $1 / 2$ copies vs 0 copies) and metabolic syndrome.

\begin{tabular}{|c|c|c|c|c|}
\hline & \multicolumn{2}{|c|}{ Simple model } & \multicolumn{2}{|c|}{ Adjusted model* } \\
\hline & OR $(95 \% \mathrm{Cl})$ & $P$ value & OR $(95 \% \mathrm{Cl})$ & $P$ value \\
\hline Haplotype 2: Bc/l & $0.93(0.85-1.02)$ & 0.107 & $0.93(0.85-1.02)$ & 0.106 \\
\hline Haplotype 3: GR-9beta & $1.03(0.94-1.14)$ & 0.474 & $1.05(0.95-1.15)$ & 0.371 \\
\hline Haplotype 4: N363S & $1.03(0.87-1.22)$ & 0.755 & $1.01(0.85-1.21)$ & 0.894 \\
\hline Haplotype 5: ER22/23EK + GR-9beta & $0.90(0.73-1.11)$ & 0.317 & $0.91(0.73-1.12)$ & 0.374 \\
\hline
\end{tabular}

*Adjusted for age, sex, education level and smoking status.

$\mathrm{Cl}$, confidence interval; OR, odds ratio.

frequencies we reported in another large ethnically similar cohort in the Netherlands (22).

\section{Effect of GR haplotypes on MetS presence}

Logistic regression analysis showed no effects on the functional GR receptor haplotypes on MetS presence $(P>0.05$, Table 2$)$. A sensitivity analysis using the IDF criteria for MetS did not change this result (data not shown). For GR haplotype 4 that contains the N363S polymorphism, there was a significant interaction between haplotype carrier status and $\operatorname{sex}\left(\chi^{2}(\mathrm{df}=1)=4.22\right.$, $P=0.040)$, age $\left(\chi^{2}(\mathrm{df}=1)=9.70, P=0.002\right)$ and education $\left(\chi^{2}(\mathrm{df}=2)=8.51, \quad P=0.014\right)$; therefore, we performed stratified analysis to explore these associations.

Table 3 Results of stratified analysis for the association between glucocorticoid receptor haplotype 4 carrier status ( $1 / 2$ copies vs 0 copies) and metabolic syndrome.

\begin{tabular}{|c|c|c|c|}
\hline \multirow[b]{2}{*}{ Subgroup } & \multirow{2}{*}{$\begin{array}{c}\text { Number of } \\
\text { participants }\end{array}$} & \multicolumn{2}{|c|}{ Haplotype 4 effect } \\
\hline & & OR $(95 \% \mathrm{Cl})$ & $P$ value \\
\hline \multicolumn{4}{|c|}{ Education status } \\
\hline Low & 2614 & $1.48(1.01-2.17)$ * & 0.039 \\
\hline Middle & 6427 & $0.83(0.60-1.15)^{*}$ & 0.497 \\
\hline High & 3165 & $0.84(0.49-1.44) *$ & 1.000 \\
\hline \multicolumn{4}{|l|}{ Age } \\
\hline$\leq 47$ & 6212 & $1.46(1.08-1.95)^{\ddagger}$ & 0.008 \\
\hline$>47$ & 6340 & $0.77(0.59-1.01)^{\ddagger}$ & 0.065 \\
\hline \multicolumn{4}{|l|}{ Sex } \\
\hline Female & 7327 & $0.84(0.63-1.12)^{\S}$ & 0.352 \\
\hline Male & 5225 & $1.22(0.92-1.62)^{\S}$ & 0.229 \\
\hline \multicolumn{4}{|l|}{ Age and sex } \\
\hline Female $\leq 47$ & 3681 & $1.18(0.72-1.93)^{\S}$ & 1.000 \\
\hline Female $>47$ & 3646 & $0.68(0.45-1.04)^{\S}$ & 0.096 \\
\hline Male $\leq 47$ & 2531 & $1.77(1.14-2.77)^{\S}$ & 0.005 \\
\hline Male $>47$ & 2694 & $0.88(0.57-1.37)^{\S}$ & 1.000 \\
\hline
\end{tabular}

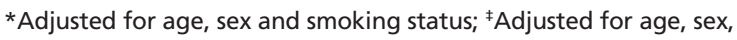
education level and smoking status; ${ }^{\S}$ Adjusted for age, education level and smoking status.

Bold values indicate statistical significance $(P<0.05)$

$\mathrm{Cl}$, confidence interval; OR, odds ratio.

\section{Stratified analysis for the effect of haplotype 4}

After stratification of our study population into two age groups, carriers of haplotype 4 at or below the median age (47 years) had a higher MetS presence (19.9 vs $14.3 \%$, adjusted odds ratio (OR) 1.46 (95\% CI: 1.08-1.95), $P=0.008$; Table 3). Further analyses showed no difference within age-strata under the median, or within strata above the median of the distribution, indicating a real difference around 47 years (data not shown). Stratification for both age and sex showed that this haplotype 4-dependent increase at younger age was particularly pronounced in men (28.1 vs $18.0 \%$, OR: 1.77 (95\% CI: 1.14-2.77), $P=0.005$; Fig. 2 and Table 3). After stratification for sex alone, no effect of haplotype 4 on MetS was observed in females and males separately $(P>0.05$; Table 3$)$. Haplotype 4 significantly increased

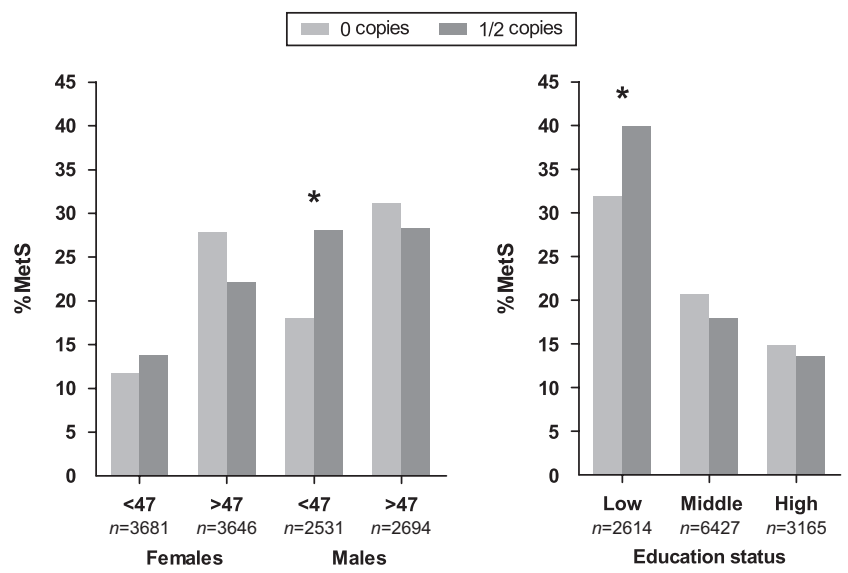

\section{Figure 2}

Metabolic syndrome presence according to haplotype 4 (N363S) carriage, stratified by sex and age quantiles (A) and education status (B). Hap4, glucocorticoid receptor haplotype 4; MetS, metabolic syndrome. ${ }^{*} P$ value $<0.05$. $P$ values in panel $A$ are adjusted for age, education level and smoking status. $P$ values in panel $B$ are adjusted for age, sex and smoking status. 
the odds for MetS in individuals with a low educations status (39.9 vs 31.9\%, OR: 1.47 (95\% confidence interval (CI) 1.08-2.01), $P=0.015$; Fig. 2 and Table 3), but not in individuals with middle or high education status $(P>0.05)$. Haplotype 4 frequencies were not significantly different between the strata for education status, age, sex, or age and sex $\left(\chi^{2}\right.$ tests, all $P$ values $\left.>0.2\right)$. Sensitivity analyses using the IDF criteria for MetS showed that haplotype 4 selectively increased MetS presence in individuals at or below the median age of 47 (OR: 1.41 (95\% CI: 1.07-1.86), $P=0.010$ ), and in men at or below the age of 47 (OR: 1.68 (95\% CI: 1.11-2.55), $P=0.007)$. In contrast to what we found when using ATPIII criteria for MetS, haplotype 4 did not significantly increase the presence of IDF-MetS in low educated individuals (OR: 1.27 (95\% CI: 0.87-1.85), $P=0.375)$.

\section{Discussion}

In this study, a glucocorticoid receptor haplotype (marked by the N363S polymorphism), which is known to increase glucocorticoid sensitivity, increased the risk of MetS, but only in specific subgroups of our study population. Although no main effect was observed when the entire cohort was analyzed, a selective increase was seen in younger males, and in people of low education status. Our finding that haplotype 4 increases MetS prevalence specifically in low-educated individuals might indicate a gene-environment interaction, in which a genetic constitution consisting of increased glucocorticoid sensitivity only results in an adverse cardiometabolic risk profile against a background of lower educational levels. One explanation for this observation could be that low education status, indicative of lower socioeconomic status, is associated with lifestyle factors that promote MetS (30), which may potentiate the metabolic consequences of increased glucocorticoid sensitivity. Alternatively, socioeconomic status might be related to altered glucocorticoid signaling. Recently, we reported an association between low socioeconomic status and increased long-term cortisol levels in children (31). Although in this study, we only examined adults, a chronic increase in cortisol levels would be expected to augment the metabolic effects of increased glucocorticoid sensitivity. Our study is limited by the fact that we did not have information about cortisol levels.

In vitro studies have shown that the polymorphism, N363S, which marks GR haplotype 4, is associated with increased transactivational activity of the GR $(13,14)$.
This is in line with increased MetS presence because transactivation is thought to be responsible for the metabolic effects of glucocorticoids (15), which include dyslipidemia, insulin resistance and central adiposity (5).

A major strength of this study is that for the first time, we were able to study the effects of GR haplotypes on MetS presence in a large, well-phenotyped populationbased cohort study. Previously, it has been shown that the participants in this cohort form a good representation of inhabitants of the north of the Netherlands (32). This also means that the Lifelines cohort consists almost exclusively of indigenous Dutch, which limits the extent to which our results can be extrapolated to other ethnic populations. In our study, we chose to focus on MetS presence, and not on associations with mean levels of HDL cholesterol, triglycerides, blood pressure and adiposity. Because MetS presence has a clear prognostic value (2), this allowed us to examine the clinical relevance of GR haplotypes.

Earlier studies investigating the associations between GR variations and the cardiometabolic phenotype were substantially smaller, and often included a range of different metabolic outcomes (10, 11, 16, 17, 18, 19, 20). Both small sample size and a high number of statistical tests increase the risk of type I error (i.e. false positives). Although no study design can completely eliminate this risk, we took several measures to reduce it. First, we only used one outcome measure: MetS presence. Secondly, we limited the number of secondary analyses performed by using a stepwise approach where stratified analyses were only performed when a genotype-phenotype interaction significantly improved the model. Thirdly, we used multiple testing adjustment to curtail the risk of type I error in our stratified analyses.

Unlike genome-wide association studies, we only studied functional variations in the GR gene, using a hypothesis-driven approach. Our study design was based on both in vitro and clinical research, and we therefore only included variants with a known influence on glucocorticoid signaling. Based on results obtained from dexamethasone suppression tests $(9,18)$ and for haplotype 5 also from functional in vitro studies (13), we expected an increased prevalence of MetS in association with haplotype 2 , which is marked by the polymorphism $B c l I$, and a decreased prevalence of MetS in haplotype 5, which is marked by ER22/23EK. Several factors could contribute to the lack of associations in this study. It could be speculated that haplotypes 2 and 5 lead to such subtle differences in glucocorticoid sensitivity and that they do not result in an altered MetS prevalence. Both BclI and ER22/23EK have been associated with 
differences in negative feedback of glucocorticoids on the hypothalamus-pituitary-adrenal axis $(9,18)$. A chronic slightly altered glucocorticoid sensitivity may therefore be partly compensated by altered cortisol levels, in which a relative hypersensitivity results in lower cortisol levels (in haplotype 2), and hyposensitivity results in increased cortisol (haplotype 5), thereby offsetting the change in glucocorticoid sensitivity. Another explanation for the lack of effect of haplotypes 2 and 5 may be that we did not examine individuals at an age during which they are particularly at risk for the modulatory effects of these haplotypes on MetS presence. ER22/23EK presence has been associated with beneficial effects on the lipid profile in men older than 53 years of age (18), whereas our present cohort mainly consists of adults of a younger age. Likewise, the BclI polymorphism was recently associated with increased insulin resistance and body weight, but this was in a population with a mean age of 65 with a high rate of type 2 diabetes mellitus (10).

In conclusion, we found that GR receptor haplotype 4, which is known to be associated with increased glucocorticoid sensitivity and increased transactivational activity of the GR, is associated with an increase in metabolic syndrome prevalence, specifically in young male adults and in individuals with low education status. These findings suggest that the association between glucocorticoid signaling and metabolic health is modulated by age, sex and socioeconomic status.

\section{Declaration of interest}

The authors declare that there is no conflict of interest that could be perceived as prejudicing the impartiality of the research reported.

\section{Funding}

The last author (Dr E F C van Rossum) is supported by the Netherlands Organization for Scientific Research (NWO) grant no. 916.96.069, the Thrasher Research Fund, grant no. TRF11643 and an Erasmus MC fellowship.

\section{Author contribution statement}

V L W, J W K and E F C V R designed the study. V L W analyzed the data and wrote the first draft of the manuscript. JWK aided in constructing the haplotypes. R P S was involved in designing the methodology of the Lifelines cohort. V L W, J W K, E L T V A, O H F, R P S and E F C V R contributed to the interpretation of the data and writing of the manuscript.

\section{Acknowledgements}

The authors wish to gratefully acknowledge the staff of the Lifelines Cohort Study, the contributing research centers delivering data to Lifelines and the study participants.

\section{References}

1 Eckel RH, Grundy SM \& Zimmet PZ. The metabolic syndrome. Lancet 2005365 1415-1428. (doi:10.1016/S0140-6736(05)66378-7)

2 Mottillo S, Filion KB, Genest J, Joseph L, Pilote L, Poirier P, Rinfret S, Schiffrin EL \& Eisenberg MJ. The metabolic syndrome and cardiovascular risk a systematic review and meta-analysis. Journal of the American College of Cardiology 201056 1113-1132. (doi:10.1016/ j.jacc.2010.05.034)

3 Grundy SM. Metabolic syndrome pandemic. Arteriosclerosis, Thrombosis, and Vascular Biology 200828 629-636. (doi:10.1161/ ATVBAHA.107.151092)

4 Quax RA, Manenschijn L, Koper JW, Hazes JM, Lamberts SWJ, van Rossum EFC \& Feelders RA. Glucocorticoid sensitivity in health and disease. Nature Reviews Endocrinology 20139 670-686. (doi:10.1038/ nrendo.2013.183)

5 Nieman LK, Biller BMK, Findling JW, Newell-Price J, Savage MO, Stewart PM \& Montori VM. The diagnosis of Cushing's syndrome: an endocrine society clinical practice guideline. Journal of Clinical Endocrinology and Metabolism 200893 1526-1540. (doi:10.1210/ jc.2008-0125)

6 Wester VL \& van Rossum EF. Clinical applications of cortisol measurements in hair. European Journal of Endocrinology 2015173 M1-M10. (doi:10.1530/EJE-15-0313)

7 Incollingo Rodriguez AC, Epel ES, White ML, Standen EC, Seckl JR \& Tomiyama AJ. Hypothalamic-pituitary-adrenal axis dysregulation and cortisol activity in obesity: a systematic review. Psychoneuroendocrinology 201562 301-318. (doi:10.1016/ j.psyneuen.2015.08.014)

8 Wester VL, Lamberts SW \& van Rossum EF. Advances in the assessment of cortisol exposure and sensitivity. Current Opinion in Endocrinology, Diabetes, and Obesity 201421 306-311. (doi:10.1097/ MED.0000000000000077)

9 Van Rossum EFC, Koper JW, Van Den Beld AW, Uitterlinden AG, Arp P, Ester W, Janssen JAMJL, Brinkmann AO, De Jong FH, Grobbee DE et al. Identification of the Bc/I polymorphism in the glucocorticoid receptor gene: association with sensitivity to glucocorticoids in vivo and body mass index. Clinical Endocrinology 200359 585-592. (doi:10.1046/j.1365-2265.2003.01888.x)

10 Geelen CC, van Greevenbroek MM, van Rossum EF, Schaper NC, Nijpels G, t Hart LM, Schalkwijk CG, Ferreira I, van der Kallen CJ, Sauerwein HP et al. BclI glucocorticoid receptor polymorphism is associated with greater body fatness: the Hoorn and CODAM studies. Journal of Clinical Endocrinology and Metabolism 201398 E595-E599. (doi:10.1210/jc.2012-3442)

11 Ukkola O, Perusse L, Chagnon YC, Despres JP \& Bouchard C. Interactions among the glucocorticoid receptor, lipoprotein lipase and adrenergic receptor genes and abdominal fat in the Quebec Family Study. International Journal of Obesity 200125 1332-1339. (doi:10.1038/sj.ijo.0801735)

12 Huizenga NATM, Koper JW, De Lange P, Pols HAP, Stolk RP, Burger H, Grobbee DE, Brinkmann AO, De Jong FH \& Lamberts SWJ. A polymorphism in the glucocorticoid receptor gene may be associated with an increased sensitivity to glucocorticoids in vivo. Journal of Clinical Endocrinology and Metabolism 199883 144-151. (doi:10.1210/ jc.83.1.144)

13 Russcher H, Smit P, Van Den Akker ELT, Van Rossum EFC, Brinkmann AO, De Jong FH, Lamberts SWJ \& Koper JW. Two polymorphisms in the glucocorticoid receptor gene directly affect glucocorticoid-regulated gene expression. Journal of Clinical Endocrinology and Metabolism 200590 5804-5810. (doi:10.1210/ jc.2005-0646)

14 Charmandari E, Ichijo T, Jubiz W, Baid S, Zachman K, Chrousos GP \& Kino T. A novel point mutation in the amino terminal domain of the human glucocorticoid receptor (hGR) gene enhancing hGR-mediated 
gene expression. Journal of Clinical Endocrinology and Metabolism 2008 93 4963-4968. (doi:10.1210/jc.2008-0892)

15 Newton R \& Holden NS. Separating transrepression and transactivation: a distressing divorce for the glucocorticoid receptor? Molecular Pharmacology 200772 799-809. (doi:10.1124/ mol.107.038794)

16 Kuningas M, Mooijaart SP, Slagboom PE, Westendorp RG \& van Heemst D. Genetic variants in the glucocorticoid receptor gene (NR3C1) and cardiovascular disease risk. The Leiden 85-plus Study. Biogerontology 20067 231-238. (doi:10.1007/s10522-006-9021-2)

17 Marti A, Ochoa MC, Sanchez-Villegas A, Martinez JA, MartinezGonzalez MA, Hebebrand J, Hinney A \& Vedder H. Meta-analysis on the effect of the N363S polymorphism of the glucocorticoid receptor gene (GRL) on human obesity. BMC Medical Genetics 2006750. (doi:10.1186/1471-2350-7-50)

18 Van Rossum EFC, Koper JW, Huizenga NATM, Uitterlinden AG, Janssen JAMJL, Brlnkmann AO, Grobbee DE, De Jong FH, Van Duyn CM, Pols HAP et al. A polymorphism in the glucocorticoid receptor gene, which decreases sensitivity to glucocorticoids in vivo, is associated with low insulin and cholesterol levels. Diabetes $2002 \mathbf{5 1}$ 3128-3134. (doi:10.2337/diabetes.51.10.3128)

19 Van Rossum EFC, Voorhoeve PG, Te Velde SJ, Koper JW, Delemarre-Van De Waal HA, Kemper HCG \& Lamberts SWJ. The ER22/23EK polymorphism in the glucocorticoid receptor gene is associated with a beneficial body composition and muscle strength in young adults. Journal of Clinical Endocrinology and Metabolism 200489 4004-4009. (doi:10.1210/jc.2003-031422)

20 van Rossum EFC, de Jong FJ, Koper JW, Uitterlinden AG, Prins ND, van Dijk EJ, Koudstaal PJ, Hofman A, de Jong FH, Lamberts SWJ et al. Glucocorticoid receptor variant and risk of dementia and white, matter lesions. Neurobiology of Aging 200829 716-723. (doi:10.1016/ j.neurobiolaging.2006.11.016)

21 Van Den Akker ELT, Russcher H, Van Rossum EFC, Brinkmann AO, De Jong FH, Hokken A, Pols HAP, Koper JW \& Lamberts SWJ. Brief report: glucocorticoid receptor polymorphism affects transrepression but not transactivation. Journal of Clinical Endocrinology and Metabolism 200691 2800-2803. (doi:10.1210/jc.2005-2119)

22 van den Akker ELT, Koper JW, van Rossum EFC, Dekker MJH, Russcher H, de Jong FH, Uitterlinden AG, Hofman A, Pols HA, Witteman JCM et al. Glucocorticoid receptor gene and risk of cardiovascular disease. Archives of Internal Medicine 2008168 33-39. (doi:10.1001/archinternmed.2007.41)

23 Koper JW, van Rossum EF \& van den Akker EL. Glucocorticoid receptor polymorphisms and haplotypes and their expression in health and disease. Steroids 201492 62-73. (doi:10.1016/ j.steroids.2014.07.015)
24 Stolk RP, Rosmalen JG, Postma DS, de Boer RA, Navis G, Slaets JP, Ormel J \& Wolffenbuttel BH. Universal risk factors for multifactorial diseases: LifeLines: a three-generation population-based study. European Journal of Epidemiology 200823 67-74. (doi:10.1007/s10654007-9204-4)

25 Alberti KG, Eckel RH, Grundy SM, Zimmet PZ, Cleeman JI, Donato KA, Fruchart JC, James WP, Loria CM, Smith SC Jr et al. Harmonizing the metabolic syndrome: a joint interim statement of the International Diabetes Federation Task Force on Epidemiology and Prevention; National Heart, Lung, and Blood Institute; American Heart Association; World Heart Federation; International Atherosclerosis Society; and International Association for the Study of Obesity. Circulation 2009120 1640-1645. (doi:10.1161/ CIRCULATIONAHA.109.192644)

26 Alberti KGMM, Zimmet P \& Shaw J. Metabolic syndrome - a new world-wide definition. A consensus statement from the international diabetes federation. Diabetic Medicine 200623 469-480. (doi:10.1111/ j.1464-5491.2006.01858.x)

27 Purcell S, Neale B, Todd-Brown K, Thomas L, Ferreira MAR, Bender D, Maller J, Sklar P, De Bakker PIW \& Daly MJ. PLINK: a tool set for whole-genome association and population-based linkage analyses. American Journal of Human Genetics 200781 559-575. (doi:10.1086/519795)

28 Stephens M, Smith NJ \& Donnelly P. A new statistical method for haplotype reconstruction from population data. American Journal of Human Genetics 200168 978-989. (doi:10.1086/319501)

29 Stephens M \& Donnelly P. A comparison of bayesian methods for haplotype reconstruction from population genotype data. American Journal of Human Genetics 200373 1162-1169. (doi:10.1086/379378)

30 Park Y-W, Zhu S, Palaniappan L, Heshka S, Carnethon MR \& Heymsfield SB. The metabolic syndrome: prevalence and associated risk factor findings in the US population from the Third National Health and Nutrition Examination Survey, 1988-1994. Archives of Internal Medicine 2003163 427-436. (doi:10.1001/ archinte.163.4.427)

31 Rippe RC, Noppe G, Windhorst DA, Tiemeier H, van Rossum EF, Jaddoe VW, Verhulst FC, Bakermans-Kranenburg MJ, van IJzendoorn MH \& van den Akker EL. Splitting hair for cortisol? Associations of socio-economic status, ethnicity, hair color, gender and other child characteristics with hair cortisol and cortisone. Psychoneuroendocrinology 201566 56-64. (doi:10.1016/ j.psyneuen.2015.12.016)

32 Klijs B, Scholtens S, Mandemakers JJ, Snieder H, Stolk RP \& Smidt N. Representativeness of the LifeLines Cohort Study. PLoS ONE 201510 e0137203. (doi:10.1371/journal.pone.0137203)

Received 23 June 2016

Revised version received 10 September 2016

Accepted 15 September 2016 